\title{
A study of the mechanism of consolidating metal powder under explosive- implosive shock waves
}

\author{
Juxian Gao, Binghuang Shao, and Ke Zhang \\ Institute of Mechanics, Academia Sinica, Beijing 100080, China
}

(Received 6 August 1990; accepted for publication 24 January 1991)

\begin{abstract}
A study of the two-dimensional flow pattern of particles in consolidation process under explosive-implosive shock waves has been performed to further understand the mechanism of shock-wave consolidation of metal powder, in which bunched low-carbon steel wires were used instead of powder. Pressure in the compact ranges from 6 to $30 \mathrm{GPa}$. Some wires were electroplated with brass, some pickled. By this means, the flow pattern at particle surfaces was observed. The interparticle bonding and microstructure have been investigated systematically for the consolidated specimens by means of optical and electron microscopy, as well as by microhardness. The experimental results presented here are qualitatively consistent with Williamson's numerical simulation result when particle arrangement is close packed, but yield more extensive information. The effect of surface condition of particle on consolidation quality was also studied in order to explore ways of increasing the strength of the compacts. Based on these experiments, a physical model for metal powder shock consolidation has been established.
\end{abstract}

\section{INTRODUCTION}

Shock waves have been used to consolidale metal powders. With this method it is possible to obtain consolidated materials that retain the desirable nonequilibrium properties of the initial powder. ${ }^{1,2}$ This method has been used also to consolidate ceramic powders ${ }^{3}$ or to activate them ${ }^{4,5}$ by introducing a high defect density that is beneficial to the subsequent sintering process. These characteristics are very attractive for the materials science and shock physics community, because a new way to design new materials with ideal properties can be found. In studying the mechanism of dynamical consolidation of metal powder the specimens were analyzed and tested mainly by optical and clcctron microscopy as well as by microhardness. ${ }^{6-12}$ Because the dynamic consolidation process is a very complex three-dimensional regime, the distribution of powder particles is random. So it is very difficult to understand the detailed changes made before and after explosive consolidation. Therefore, some phenomena observed are local and occasional, making models constructed on the basis of these also localized. In fact, it is very difficult to reach a complete understanding about the experimental facts ${ }^{13-18}$ bccause of the complexity of the phenomena themselves. So far, the mechanism is not fully clear. Since numerical simulation can describe macroscopic dynamical consolidation patterns and indicate changes in parameters it is an effective method for investigating the mechanism ${ }^{19}$ (assuming the computer capacity is sufficient). Although numerical simulation of dynamical consolidation at the particle level may help us understand fully the mechanism of consolidation, this three-dimensional numerical simulation is limited by insufficient computing resources. Recently, Williamson and Ber$\mathrm{ry}^{20,21}$ and Flinn et al. ${ }^{22}$ developed a model at the particle level using a two-dimensional finite difference code (CSQ II), which is capable of handling multiple materials, to investi- gate the phenomena occuring during dynamic consolidation of metal powder. In their model the individual particles were assumed to be infinitely long cylinders rather than spheres. Some very interesting results were obtained by their numerical simulation. Even so, it is difficult to describe the flow pattern of the particle surfaces, because that requires finer computational meshes, which implies a larger computer capacity, However, it is possible to explore experimentally the flow pattern of particle surfaces, if bunched electroplated metallic wires are used instead of powder. The section perpendicular to the axis of the compact of bunched wires displays a two-dimensional flow pattern of particles. No substantive difference between two-dimensional and three-dimensional phenomena exists, although three-dimensional phenomena may be more complex. It is easy to contrast the phenomena before and after dynamic consolidation in the two-dimensional experiments, and to analyze the effect of certain factors on consolidation.

In this paper, bunched metal wires (in lieu of powder) were consolidated by explosive-implosive shock waves in order to investigate the mechanism of metal powder consolidation. Some significant results have been obtained.

\section{EXPERIMENTS}

Bunched low-carbon steel wires with three different surface conditions were prepared for consolidation. Low-carbon steel wires" $(0.10 \%)$ were first pickled, then electroplated with brass $(62 \% \mathrm{Cu}, 0.8 \% \mathrm{Sn}, 36.9 \% \mathrm{Zn}$, others $0.3 \%)$ to investigate the flow pattern at the surface of the particles. A pickled surface condition wire and a retained oxide surface condition wire were used to study contrasting effects of oxide on consolidation. The diameter of the wires ranged from 300 to $2500 \mu \mathrm{m}$. The initial density of the specimens was determined with a quantitative microscopy apparatus. 
The explosive-implosive shock wave was produced by slide detonation of a cylindrical charge. The explosive compaction assembly is shown schematically in Fig. 1. The mixed explosives of RDX ${ }^{\#}$ (cyclonite) and AN" (ammonium nitrate fuel mixture) in different proportions were used in our experiments. The composition proportion of the mixed explosives, initial density, and charge size were adjusted to change detonation pressure $P_{H}$, specific impulse $I$ (the impulse per unit surface area of the capsule), and specific energy using explosive energy per unit mass powder. In the experiments the detonation velocity was measured, and based on this the detonation parameters were calculated. The pressure in the compact ranges from 6 to $30 \mathrm{GPa}$. The thickness, composition, morphology, and microhardness of the brass layer and the particles were observed and analyzed by optical microscopy, SEM, energy spectrum, and microhardness before and after consolidation. The welding fraction and melting area fraction were measured with a quantitative microscopy apparatus.

\section{RESULTS}

Several representative experimental results are shown in Table I. It is very clear that under the same condition bunched wires with a pickled or brass-plated surface were completely consolidated, but bunched wires with oxide were hardly consolidated. It is worthy noticing that the initial surface conditions of the wire plays an important role in explosive consolidation whether for thin or thick wires.

The results of Williamson's numerical simulation are shown in Figs. 2 and 3. Figure 2 shows the changing particle shape during compaction and was overlayed by a dot distribution wherein the dot density in a region is proportional to the temperature in that region. If the particles are arranged as close packing, it can be seen from the figure that individual particles do not undergo significant relative movement. However, a great deal of deformation at or near the particle surface is required to fill in the void among the particles during the consolidation. The regions of interstitial collapse, where the material deformation is the greatest, become local hot spots in the compact, because plastic work is transformed into heat which in turns heats that region. Figure 3 describes the temperature history at various locations, and



FIG. 1. Illustration of explosive consolidation assembly.

the peaks in the figure correspond in time to the instant of final void closure. The highest temperatures are 2000-2500 $\mathrm{K}$, depending on the position. The impacting particle surfaces result in a highly compressed local region which accounts for a portion of the temperature increase shown. The residual temperature, which is primarily due to deformation, remains high in the regions with large strain. In the interior of the particles, where the strain is much less, the temperature increase is very small.

It is very exciting to contrast our experimental results with numerical simulation results. ${ }^{22}$ An etched photomicrograph of a section perpendicular to the axis of the compact that was consolidated with bunched brass-plated wires is shown in Fig. 4. The consistency between the numerical simulation and the experimental results is apparent, and is shown in Figs. 2 and 4. Of special note, the distribution of high-temperature regions is similar when the wire arrangment is close packed. Williamson's calculated results were obtained under plane shock waves. Our experiments were carried out under explosive-implosive shock waves. Because the wire diameter is far smaller than the diameter of the capsule and at a position nearer to the capsule wall, i.e., its curvature radius is very big, the form of the shock waves approaches that of plane shock waves, so similar phenomena in Figs. 2 and 4 can be observed. In Fig. 4 the distribution of regions that collected brass corresponds to the distribution of the high-temperature regions in Fig. 2. It is experimental-

TABLE I. Experimental data of shock-wave consolidation.

\begin{tabular}{|c|c|c|c|c|c|c|c|c|c|c|c|}
\hline \multirow[b]{2}{*}{ No. } & \multirow[b]{2}{*}{$\begin{array}{c}\text { Wire } \\
\text { diameter } \\
(\mu \mathrm{m})\end{array}$} & \multirow[b]{2}{*}{$\begin{array}{l}\text { Surface } \\
\text { condition }\end{array}$} & \multirow[b]{2}{*}{$\begin{array}{l}\text { Initial } \\
\text { density } \\
(\%)\end{array}$} & \multicolumn{2}{|c|}{ Container } & \multirow[b]{2}{*}{$\begin{array}{c}\text { Detonation } \\
\text { velocity } \\
(\mathrm{mm} / \mu \mathrm{s})\end{array}$} & \multirow[b]{2}{*}{$\begin{array}{c}\text { Detonation } \\
\text { pressure } \\
\mathrm{GPa}\end{array}$} & \multirow{2}{*}{$\begin{array}{c}\text { Specific } \\
\text { impulsion } \\
\left(\mathrm{J} / \mathrm{cm}^{2} \mathrm{~s}\right)\end{array}$} & \multirow[b]{2}{*}{$\begin{array}{c}\text { Loading } \\
\text { time } \\
(\mu s)\end{array}$} & \multirow[b]{2}{*}{$\begin{array}{c}\text { Bonding } \\
(\%)\end{array}$} & \multirow[b]{2}{*}{$\begin{array}{c}\text { Melting } \\
\text { area } \\
(\%)\end{array}$} \\
\hline & & & & $\begin{array}{c}\text { Outer } \\
\text { diameter } \\
(\mathrm{mm})\end{array}$ & $\begin{array}{c}\text { Wall } \\
\text { thickness } \\
(\mathrm{mm})\end{array}$ & & & & & & \\
\hline 1 & 2370 & brass plated & 76 & $\varnothing 25$ & 1 & 4.8 & 5.8 & 125 & 14.1 & 100 & 4 \\
\hline 2 & 2350 & pickled & 76 & $\varnothing 25$ & 1 & 4.5 & 5.1 & 134 & 15.1 & 100 & 6 \\
\hline 3 & 2500 & oxide & 87 & $\varnothing 25$ & 1 & 4.8 & 6.5 & 149 & 15.5 & 0 & 0 \\
\hline 4 & 540 & brass plated & 82 & $\varnothing 14$ & 1.5 & 5.4 & 9.3 & 290 & 14.1 & 100 & 15 \\
\hline 5 & 700 & pickled & 81 & $\varnothing 14$ & 1.5 & 4.1 & 4.8 & 196 & 18.5 & 100 & 5 \\
\hline 6 & 500 & oxidc & 68 & $\varnothing 14$ & 1.5 & 4.1 & 4.8 & 196 & 18.5 & 5 & 1 \\
\hline
\end{tabular}





(b) Time $=20 \mathrm{~ns}$

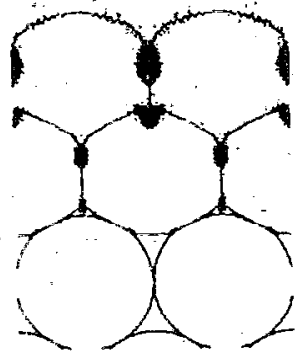

(c) Time $=40 \mathrm{~ns}$

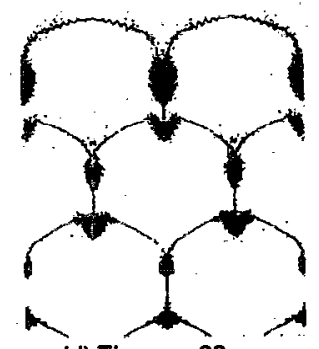

(d) Time $=60 \mathrm{~ns}$

FIG. 2. The calculated results of temperature distribution. Black points denote high temperature (see Ref, 22 ).

ly evidenced by micrography and microhardness that the melting occurred in the region that collected brass. Figure 5 shows the general situation of one section of the compact. The thickness change of the brass layer shows the flow of the particles surface. In Fig. 5 point A marks the wave brassmelting region, which illustrates that phenomena occurred during the flow process of the particle surface. Point $B$ in Fig. 5 and point $O$ in Fig. 4 indicate high-temperature regions in which brass was collected from forming jet penetration. This is very good evidence of jet penetration phenomenon. The entrance of the cavity is very small, but the cavity

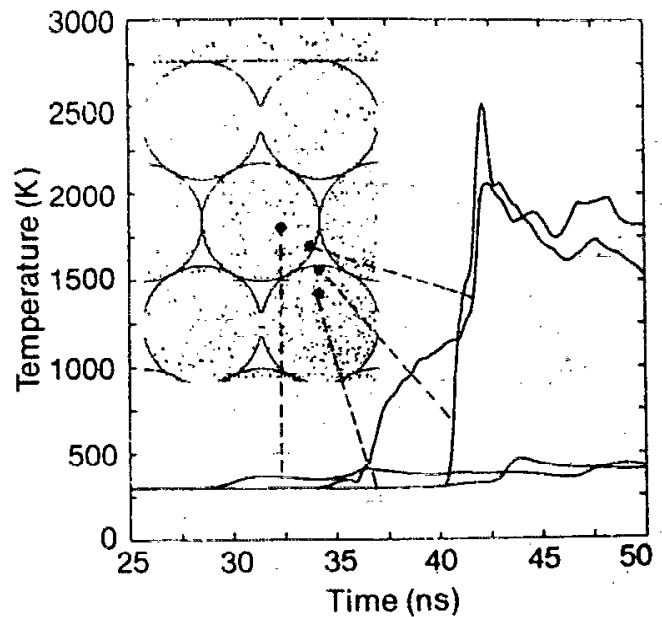

FIG. 3. The calculated results of temperature history at different positions in the particles (see Ref. 22).

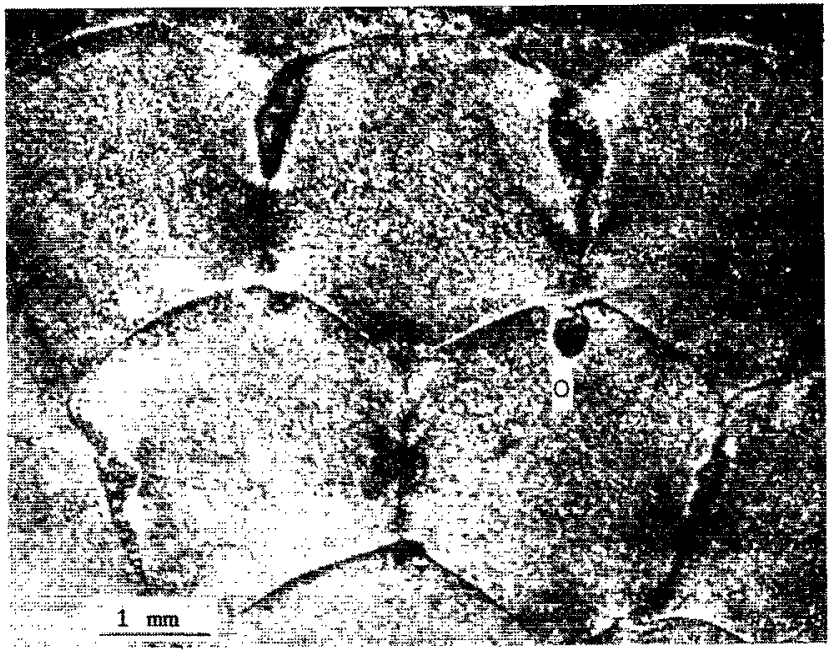

FIG. 4. Photomicrograph of a section perpendicular to the axis of the compact with brass-plated wires that shows flow pattern of brass-plated layer. The region that collected brass that was melted is consistent with the hightemperaturc region distribution in Williamson's numerical simulation (see Fig. 2).

itself is much bigger, and is filled with a copper-iron alloy. The energy spectrum analysis shows that a complex alloy $\left(\mathrm{Cu}_{n} \mathrm{Fe}_{x} \mathrm{Zn}_{y} \mathrm{Sn}_{z}\right)$ was produced in the high-temperature zones among the particles and in the cavity. Their microhardness is about $H_{v}=668$. Point $\mathrm{C}$ in Fig. 5 and Fig. 6 show the microcracks in the high-temperature area, which were caused by a different thermal dilatation between two



FIG. 5. Polished section perpendicular to the axis of the compact that is consolidated with brass-plated wires. Point A indicates losing steady phenomenon that occurred during the flow process of the particle surface; point $B$ points out the penetrating cavity which is filled with a copper-iron alloy by jet penetration; point $C$ indicates a cracked region in the new alloy phases; point $D$ points out a nonmelting welding region in which no brass exists. 


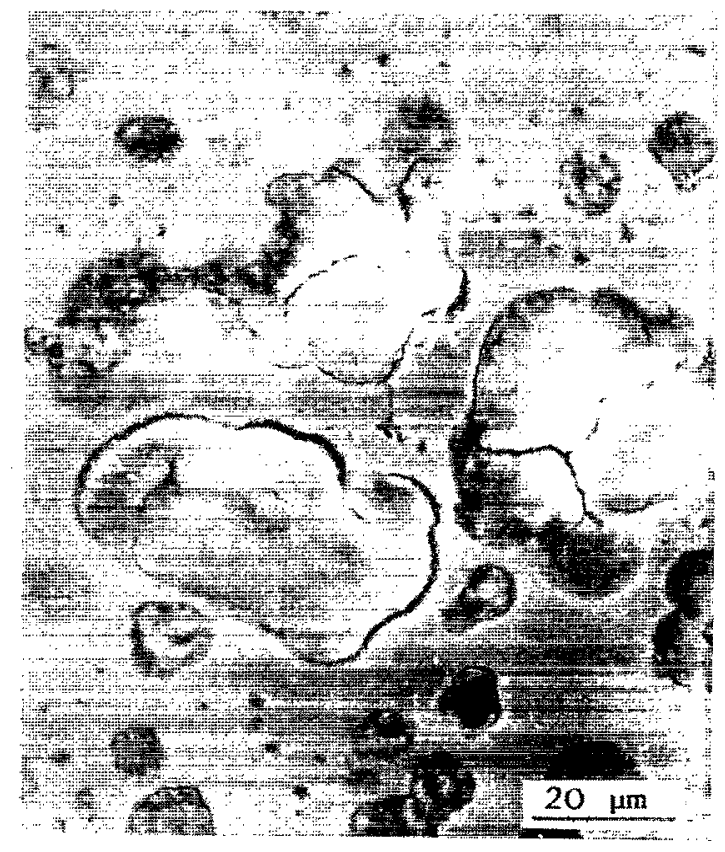

FIG. 6. The cracks in the high-temperature region as a result of forming some new alloys.

different alloy phases during the cooling process. In all boundaries between particles, except for the high-temperature region energy spectrum analysis shown, the composition of the brass layer does not change; its microhardness is $H_{1}=241$. Point $\mathrm{D}$ in Fig. 5 indicates the nonmelting welding region, in which no brass exists at all. The direct bonding region between the particles has been observed using SEM and no difference in the morphology between the bonding position and the particle itself can be discerned. This indicates nonmelting bonding.

The result of measured brass layer thickness on the section perpendicular to the axis of the compact is shown in Fig. 7. The initial thickness of the brass-plated layer is $15 \mu \mathrm{m}$.

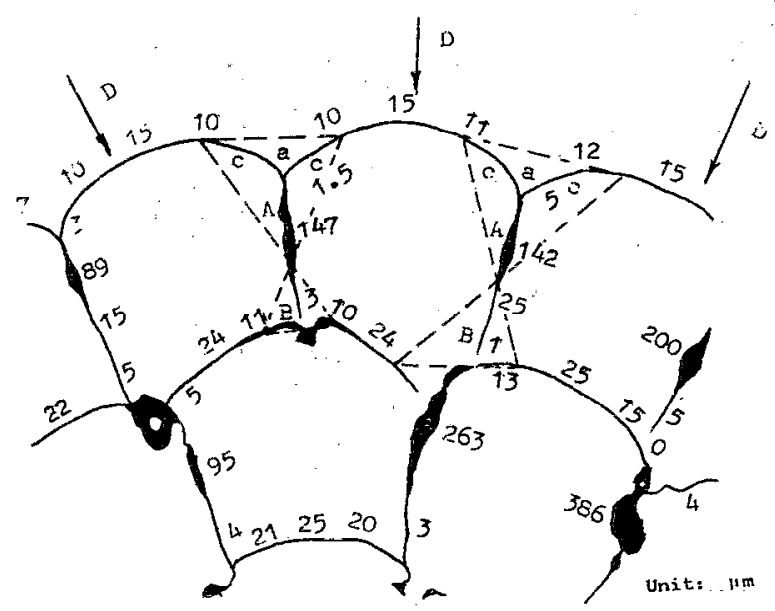

FIG. 7. The resulting measured brass thickness $(\mu \mathrm{m})$.
The numbers in the figure represent the thickness value of the brass layer. The mean change of the thickness is about 7 $\mu \mathrm{m}$ except in the collecting brass high-temperature region. The wire diameter is $2370 \mu \mathrm{m}$, so it is about $0.3 \%$. The thickness change of the brass layer for $540-\mu \mathrm{m}$-diam wire was also measured: Its relative change is about $0.5 \%$. These phenomena prove that the flow of material is concentrated on the very thin layer of the particle surface, so the shock energy is mainly deposited at the particle surface. The thickness change of the brass layer that is near void among the particles is the largest, and the thickness of the brass layer at the initial peripheric contact points hardly changes. No rotation of the particle itself occurs under particles in the closepacked arrangement condition, but the movement of nonclose-packed particles is complex.

A vortex in the high-temperature melting region, (a very interesting phenomenon) was observed, and is shown in Fig. 8. The energy spectrum analysis shows that composition in this region is not uniform (see Table II). It can be imagined that the vortex was formed during the brass layer flowing process, and that the composition in the region had not reached uniformity yet because of fast cooling.

In order to prove further the phenomena observed in the compact of brass-plated wires, and to make clear some problems such as the temperature rise range, cooling mechanism, etc., the compacts of pickled low-carbon steel wires were systematically studied by optical and electron microscopy and microhardness. Figure 9 shows an etched photomicrograph of a section perpendicular to the axis of the compact. A common characteristic in the high-temperature region is a layer of white pure ferrite grains around a dark region that

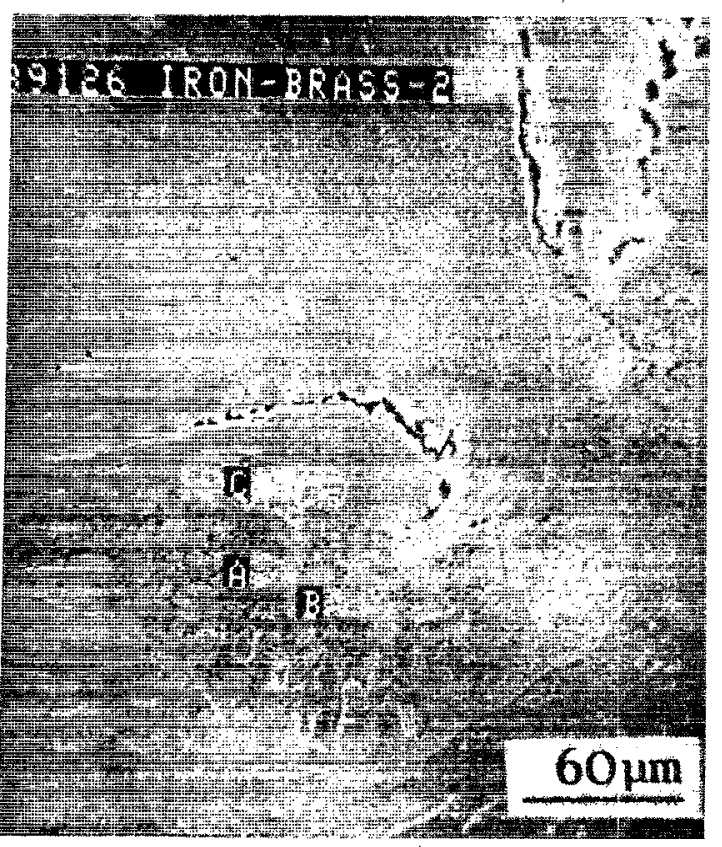

FIG. 8. Vortex phenomenon present in a high-temperature area near the capsule wall on the section perpendicular to the axis of compact with brassplated wires. It can be seen that the composition in the region is not uniform. 
TABLE II. Chemical composition in different positions.

\begin{tabular}{|c|c|c|c|c|}
\hline \multirow[b]{2}{*}{$\begin{array}{l}\text { Fraction } \\
\text { element }\end{array}$} & \multicolumn{3}{|c|}{ Area } & \multirow[b]{2}{*}{ Mean value } \\
\hline & $\begin{array}{c}\text { A } \\
\text { White area }\end{array}$ & $\begin{array}{c}\mathrm{B} \\
\text { Dark area }\end{array}$ & $\underset{\text { Island }}{C}$ & \\
\hline $\mathrm{Fe}$ & 3.84 & 19.04 & 55.96 & 27.32 \\
\hline $\mathrm{Cu}$ & 86.61 & 71.10 & 32.06 & 63.53 \\
\hline $\mathrm{Zn}$ & 10.53 & 9.84 & 11.93 & 9.13 \\
\hline Sn & 0.003 & 0.015 & 0.044 & 0.02 \\
\hline
\end{tabular}

seems to have a cast morphology. The ordinary morphology of the wire is both ferrite and pearlite, so the appearance of the layer of pure white ferrite grains is a result of coring during the cooling process of the melting region. The dark region was proved to be lathy martensite by means of optical and electron micrography, shown in Fig. 10. Its microhardness ranges from $H_{v}=510$ to 730 . The microhardness of the layer of white pure ferrite grains around it ranges between $H_{v}=170$ and 195 , which is the same as the initial microhardness of the ferrite before explosive consolidation. A nonmelting region can be seen in the lower section of Fig. 9, in which neither the melting vestige nor the phase change is observed. No difference between the welding portion morphology and the particle morphology exists (see Fig. 11). It is clear that non-melting welding occurred in this portion.

In both the brass-plated wires and the pickling wires the deformation in the particles is mainly twin. This is a com-

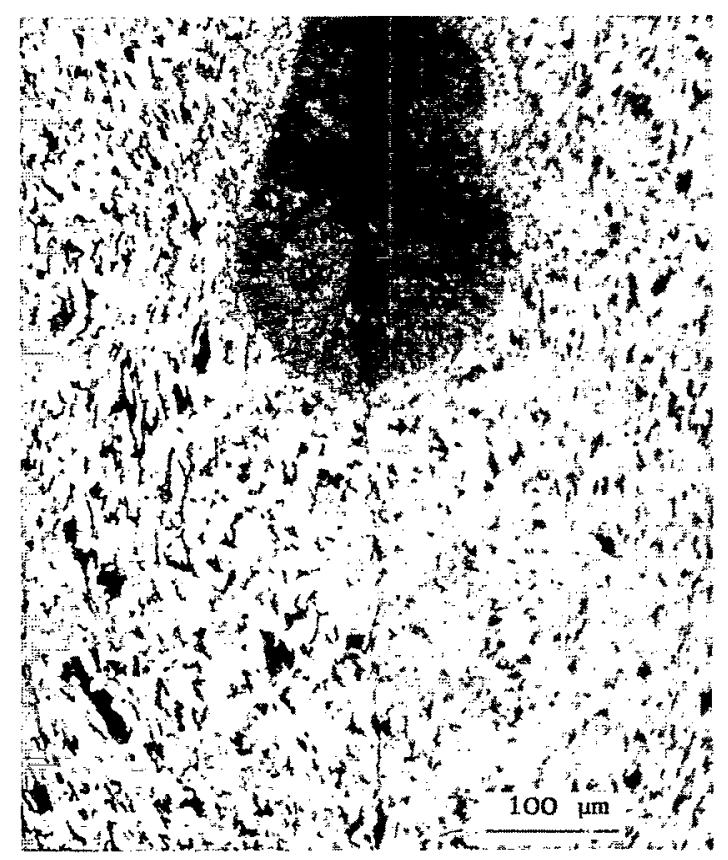

FIG. 9. The morphology of the section perpendicular to the axis of the compact that was consolidatcd with pickled wires. The upper dark area is the high-temperature area, a white layer around the dark area is pure ferrite. Below it is nonmelting welding.

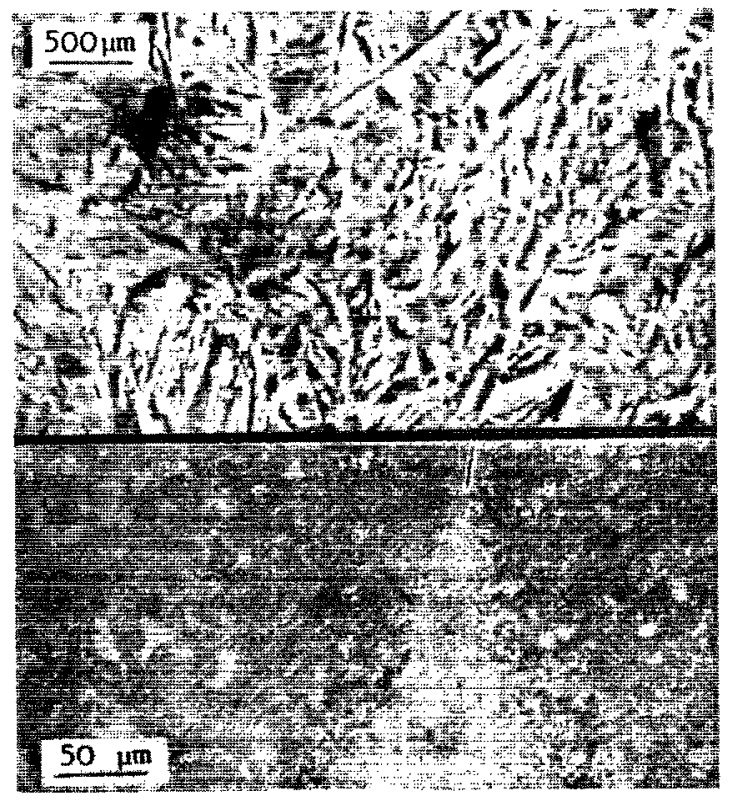

FIG. 10. The lower figure shows the high-temperature region between particles. The upper figure is the local magniflcation of the high-temperature region, verified to be lathe martensite.

mon characteristic of high-strain-rate deformation for lowcarbon steel, shown in Fig. 12.

The microhardness distribution along the section perpendicular to the axis of the compact was measured for explosive-implosive shock consolidation of the pickled lowcarbon steel wires with the initial bunched wires density 0.76 of the bulk density. Typical results are shown in Fig. 13. It

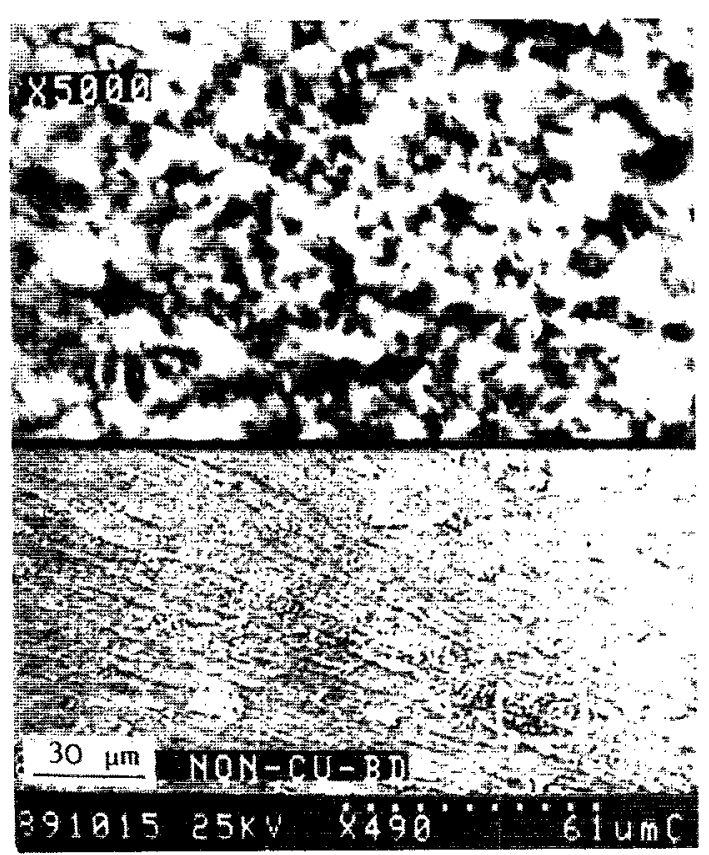

FIG. 11. The welding interface is along the white line in the lower figure. The upper figure is the local magnification of the square frame in the lower figure showing nonmelting welding. No difference between the welding interface morphology and the particle morphology can be seen. 


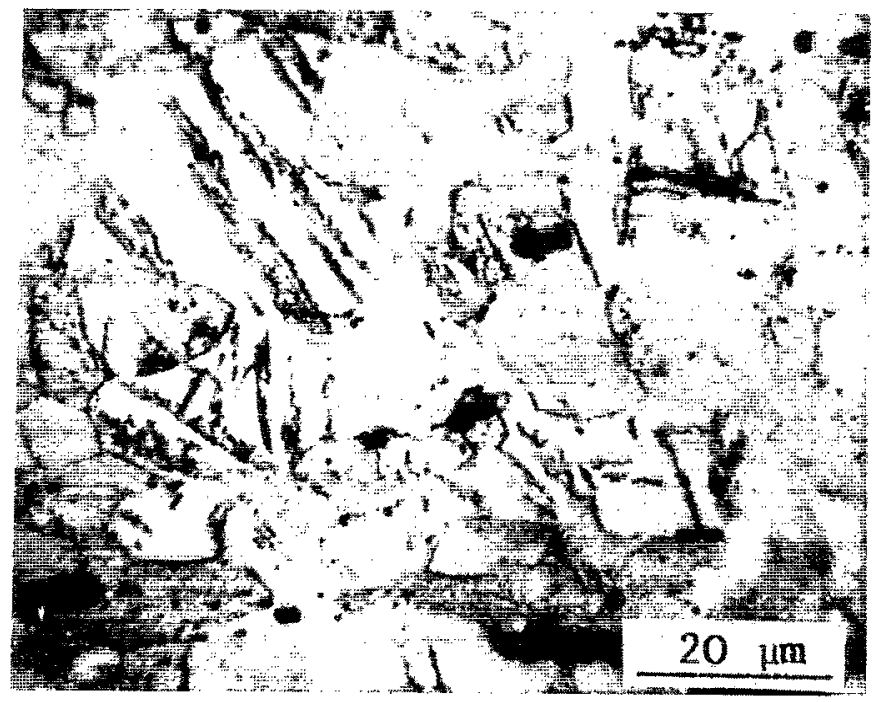

FIG. 12. Twin deformation in the particles.

shows a general pattern except in the martensite region in which the microhardness is especially high. The microhardness increases in both ferrite and pearlite from the edge to the center of the compact, which is consistent with the pressure distribution pattern. The microhardness of ferrite ranges between $H_{v}=200$ and 285. They all are higher than the original microhardness of ferrite. Also the microhardness of pearlite ranges between $H_{i}=280$ and 315 , which is higher than the original values as well, although the change is not as obvious as that of ferrite. The microhardness increment in ferrite is proportional to the twin amount and the twin orientation number. The microhardness value in the zone near the welding interface is generally higher than that in the particle itself. The difference is about $70-100 H_{v}$ units. This is obviously related to the severe plastic deformation in the zone.

\section{DISCUSSION}

In terms of the above-mentioned experimental results, we can represent the pattern of particle consolidation under explosive-implosive shock-wave loading as follows. It is assumed that the powder consists of monosize spheres, and the arrangement of spherical particles is close packed. When the shock wave sweeps past the powder the shock front is not an isocurvature surface because the propagation speed of the shock wave in space (if air exists) is much lower than that in metal particles. The duration passed a particle (the diameter of the spheres is usually of the order $10^{-2}-10^{-4} \mathrm{~cm}$ ) by the shock wave is $10^{7}-10^{9} \mathrm{~s}$, and the duration of shock loading to the consolidated powder is several microseconds. The former is much less than the latter, so the wave process in a particle may not be considered in the research of powder consolidation. Under shock-wave action the surface mass of the particle near the space moves at about twice the particle speed to create collision and friction among the particles. Collision welding among neighboring particles may occur with the collision angle $2 \beta$ ranging from $0^{\circ}$ to $72^{\circ}$ under a close-packed condition. In terms of explosive welding mech- anisms, the surface mass in the welded area will form a jet spurting out to penetrate opposite particles or to collect together forming high-temperature areas (see Fig. 5). The collision welding may make the temperature of particle surfaces rise. It is assumed that two particles come into symmetrical collision with each other at a speed $V_{f}=V_{p} / \tan \beta$, where $V_{p}$ denotes a component speed perpendicular to the particle surface. The speed field near the collision point is ${ }^{23}$

$$
\begin{aligned}
Z=(x+i y)= & \frac{h}{\pi}\left[(1+\cos \beta) \ln \left(1+\frac{\bar{V}_{*}}{V_{f}}\right)\right. \\
& -(1-\cos \beta) \ln \left(1-\frac{\bar{V}_{*}}{V_{f}}\right) \\
& -e^{i \beta} \ln \left(1+\frac{\bar{V}_{*}}{V_{f}} e^{i \beta}\right) \\
& \left.-e^{i \beta} \ln \left(1+\frac{\bar{V}_{*}}{V_{f}} e^{i \beta}\right)\right],
\end{aligned}
$$

where $h$ denotes the thickness of coming flow. Formula (1) describes the relation between value $Z$ on complex number plane and conjugate complex speed,

$$
\bar{V}_{*} / V_{f}=1 / V_{f}(u-i v) \text {. }
$$

The speed $V_{*}\left(V_{*}=u+i v\right)$ possesses a large speed gradient; its shear strain rate may be $10^{7} \mathrm{~s}^{-1}$. The temperature in the shear layer quickly rises because of high-speed shear deformation. The high temperature makes it soften, which in turn makes shear strain further concentrate on the softening layer, so an adiabatic shear layer is formed along the welding interface. This thin layer may attain a high temperature or even start melting. In the thin layer the heat transmission equation is

$$
\rho_{0} C_{i v} \frac{\delta T}{\delta t}=\tau_{i j} \dot{\gamma}_{i j}-K \frac{\delta^{2} T}{\delta x^{2}},
$$

where $\rho_{0} C_{v}(\delta T / \delta t)$ denotes increasing rate of heat internal energy in the shear layer; $\tau_{i j} \dot{\gamma}_{i j}$ denotes the plastic deformation power; $C_{n}, \rho_{0}, T$, and $t$ denote specific heat at constant volume, density, temperature, and time, respectively $\left(C_{v}=0.46 \times 10^{3} \mathrm{~J} / \mathrm{kg} \mathrm{K}\right.$ for iron $) ; \tau_{i j}$ is an equivalant shear stress, and is dependent on strain $\gamma_{i j}$, temperaturc $T$, and strain rate $\dot{\gamma}_{i j}$ :

$$
\begin{aligned}
\tau_{i j}= & \tau_{0}\left(1+\alpha \gamma_{i j}\right) \exp \left[-\beta\left(T-T_{0}\right)\right]+K \ln \dot{\gamma}_{i j} \\
& \left(\dot{\gamma}_{i j}<10^{3} \mathrm{~s}^{-1}\right) .
\end{aligned}
$$

when $\dot{\gamma}_{i j}>10^{3} \mathrm{~s}^{-1}$, the shear stress $\tau_{i j}$ is proportional to strain rate $\dot{\gamma}_{i j}{ }^{25}$ that is

$$
\tau_{i j}=\tau_{0}\left(1+\alpha \gamma_{i j}\right) \exp \left[-\beta\left(T-T_{0}\right)\right]+\mu \dot{\gamma}_{i j},
$$

where $\tau_{0}, \alpha$, and $\beta$ are material constants. $\mu$ is viscous coefficient, $\mu=0.42 \times 10^{3} \mathrm{~Pa}$ s for iron. When $\dot{\gamma}_{i j}=10^{7} \mathrm{~s}^{-1}, \tau_{i j}$ is of the order of magnitude of $10 \mathrm{GPa}$, and $\tau_{i j} \dot{\gamma}_{i j}=10^{17} \mathrm{~J} / \mathrm{m}^{3}$ s. $K\left(\delta^{2} T / \delta x^{2}\right)$ is the heat transmission loss term, and $K$ is the heat transmission coefficient $\left(K=0.5 \times 10^{2} \mathrm{~J} / \mathrm{m} \mathrm{K}\right.$ s for iron ). $T$ denotes the temperature difference between the interior and exterior of the shear layer (about $10^{3} \mathrm{~K}$ ). $\Delta x$ is the 
thickness of the adiabatic shear layer; the order of magnitude is $10^{-5}-10^{-6} \mathrm{~m}$. So the average value is $K \Delta T / \Delta x^{2}=10^{15}$ $\mathrm{J} / \mathrm{m}^{3} \mathrm{~s}$. The heat transmission loss term is compared with the shear deformation work. The former is of relatively small orders of magnitude, so the temperature in the shear layer quickly rises. In terms of the Eq. (2) the adiabatic shear work makes the temperature of the interface (shear layer) rise up to $10^{3} \mathrm{~K}$ in $\Delta t=10^{-7}-10^{-8} \mathrm{~s}$. When the vertical collision between two particles occurs or when collision angle is less than the critical angle $\beta_{c}$, the formation of microjets will be prevented. ${ }^{26}$. The critical angle $\beta_{c}$ depends on

$$
\tan \left(\beta_{c} / 2\right)=\left(2 \mu / \rho a v_{f}\right)^{1 / 2}\left[1+\left(2 \mu / \rho a v_{f}\right)^{1 / 2}\right],
$$

where $\rho, a$, and $v_{f}$ are density and thickness of the mass and the coming flow speed, respectively. When the shock wave arrives at the leeward free surface of the particle the mass near the free surface will be inserted into the space at twice the particle velocity $\left(V_{p}=2 u\right)$. The violent adiabatic friction between it and neighboring moving particles makes the frictional surface and its neighboring area increase in temperature up to $10^{3} \mathrm{~K}$. For the temperature rise due to adiabatic friction on the particle interface we can make a estimation. The heat transmission equation is

$$
\Delta \dot{Q}=\rho_{0} C_{v} \frac{\delta T}{\delta t}=P \eta \frac{V_{p}}{\Delta x}-K \frac{\delta^{2} T}{\delta x^{2}},
$$

where $p \eta V_{p} / \Delta x$ denotes the friction power term, $P$ is vertical pressure between two particles (about the order of magnitude of $10 \mathrm{GPa}$ ); $\eta$ is a friction coeffient (about $10^{-1}$ ); $V_{p}$ is the relative slide speed between two particles, which is roughly equal to the free-surface speed $(2 u)$, of the order of magnitude of $10^{3} \mathrm{~m} / \mathrm{s}$. $\Delta x$ is the thickness of the rising temperature layer from the friction, $\left(10^{-6} \mathrm{~m}\right)$. So $P \eta V_{p} / \Delta x=10^{18} \mathrm{~J} / \mathrm{m}^{3} \mathrm{~s}$. The heat transmission losing term is correspondingly $10^{5} \mathrm{~J} / \mathrm{m}^{3} \mathrm{~s}$. The latter is in relatively small orders of magnitude. Therefore, adiabatic friction can raise the temperature to $10^{3}-10^{4} \mathrm{~K}$ in $10^{-7}-10^{-8} \mathrm{~s} \cdot{ }^{24}$ Compared with the collision welding, the friction action is a more important factor contributing to the rise in temperature. In fact, the friction welding may occur on the interface (see Fig. 14). When the shock pressure is higher and the space among the particles is greater, the friction work and melting amount are greater. The melting metal on the interface under high pressure has a strong permeation capacity, which causes the local interface to be without bonding welding. As mentioned above, the estimation shows that both mechanisms, adiabatic friction and collision welding, may make the interface rise in temperature or even melt when the particles are tightly bonded together under high-pressure action. After the shock front arrives at the powder, it is pressed from a loose state to a consolidated state. The pressure and the temperature at the space closing simultaneously attain peak value. When the shock wave reflects from the center of the specimen, the consolidated powder will be subjected to a second time loading that is higher than the first time loading (if a rarefaction wave does not arrive). The second time loading is usually of the order of magnitude of $n \times 10 \mathrm{GPa}$. The temperature rising from the adiabatic compression is of relative small orders of magnitude as compared with that from the adiabatic fric-



FIG. 13. Dependence of microhardness distribution along the section perpendicular to the axis of compact on the maximum shock pressure for explosive-implosive shock consolidation of pickled low-carbon steel wires with an initial density of 0.76 of the bulk density.

tion; Williamson's calculation shows that the instantaneous temperature in the high-temperature area may reach 2000 $2500 \mathrm{~K}$. In our experiments melting vestiges have been observed in the high-temperature area and in some welding interfaces, whether for the shock consolidation of pickled low-carbon steel wires or for that of brass-plated low-carbon wires. From the melting point of pickled low-carbon steel wires, we can ascertain that the temperature in the hightemperature area was higher than $1700 \mathrm{~K}$. However, the close-packed arrangement of powder is hardly realized in practical consolidation, and the arrangement of powder is usually random. But the temperature distribution in the random arrangement of particles was not discussed in Williamson's calculations. The distribution of the high-temperature area would not be a typical case such as that in a closepacked arrangement, because both translation and rotation (the rotation may be very small) may occur in the explosive consolidating process. Photomicrography of explosive-implosive shock-compacted pickled low-carbon steel wires with random arrangement is shown in Fig. 14. Its diameter was $700 \mu \mathrm{m}$ and the initial density was 0.81 of the bulk density. It is worth notice that the high-temperature area is obviously less dense than the close-packed case. A white, bright, thin layer around the particles was observed, and was verified by optical and electron microscopy to be vestiges of melting.

The coring phenomenon was observed in the high-temperature area, i.e., pure white ferrite was first separated out from melting liquid in the melting area, and then the remaining liquid was solidified and became martensite. This shows that the cooling of the melting area resulted from thermal conduction under tremendous temperature differences between the surface and the interior of the particle. The carbon content of low-carbon steel wires used in the experiment was too low to quench the melting area immediately. That means the cooling rate for this carbon content is lower than the critical quenching rate of martensite. During the cooling 
process, coring of ferrite occurs unceasingly. The carbon content in the liquid phase for such instantaneous composition is continuously richer until the cooling rate is higher than the critical quenching rate of martensite. At that moment the liquid is condensed and quenched into martensite. The microhardness of the martensite ranges from $H_{n}=510$ to 730 , corresponding to the microhardness of martensite with a carbon content of $0.3 \%$ and $0.45 \%$, respectively. Initial carbon content of the low-carbon steel wire is $0.1 \%$. The critical quenching rate of the former is much lower than that of the latter. On the other hand, in the experimental pressure range the temperature rise from shock compression ranged roughly from 50 to $250 \mathrm{~K}$, but the cooling action of rarefaction cannot go beyond the shock compression temperature rise. Therefore, the cooling of the melting area must have resulted mainly from conduction cooling, not from rarefaction.

A large melting zone was caused by a large void among particles when the detonation pressure was high enough, that is, higher than critical detonation pressure. ${ }^{27}$ The above-mentioned experimental facts also prove conclusively that an over-large melting area leads to a series of problems such as nonuniformity of properties, contraction holes, and microcracks. If unloading tensile waves arrive at the melting area before it is condensed, this may produce cracking in the compact. In order to improve the quality of the compact the occurence of an over-large melting area should be avoided. For this reason a proper mix of different size powders is needed to achieve reduction of the size of the melting area among particles.

In fact, producing a fresh and clean surface for the particles is a necessary condition for good bonding of particles. The consolidation of the wires with oxide is more difficult than that of pickled wires, because a higher temperature and pressure for consolidation of wires is needed. In the collective area of the oxidc a new brittlc phase would be formed that would decrease the quality and the strength of the compact. Therefore, great attention should be paid to the surface treatment of the powder to obtain a high-strength compact.

The mechanism of powder consolidation under explosive-implosive shock waves is a very complex problem. Using bunched wires instead of powder may deepen our understanding of phenomena that occur in powder consolidation. This method simplifies a complex three-dimensional problem into a two-dimensional problem, i.e., what happens when bunched thin long wires are consolidated under explosive-implosive shock waves. On the section perpendicular to the axis of the compact, a two-dimensional particle movement pattern can be shown if it is assumed that explosive consolidation parameters do not change along the axis direction. Using this procedure it is relatively easy to control experimental conditions, such as surface condition, and to finely contrast morphology of particles and welding among particles before and after explosive consolidation to determine precisely the flow and deformation pattern of particles. It is very difficult to investigate these phenomena under explosive consolidation of a powder. The above-mentioned results reveal a general regularity of explosive consolidation of metal powder, although the regularities possess qualitative

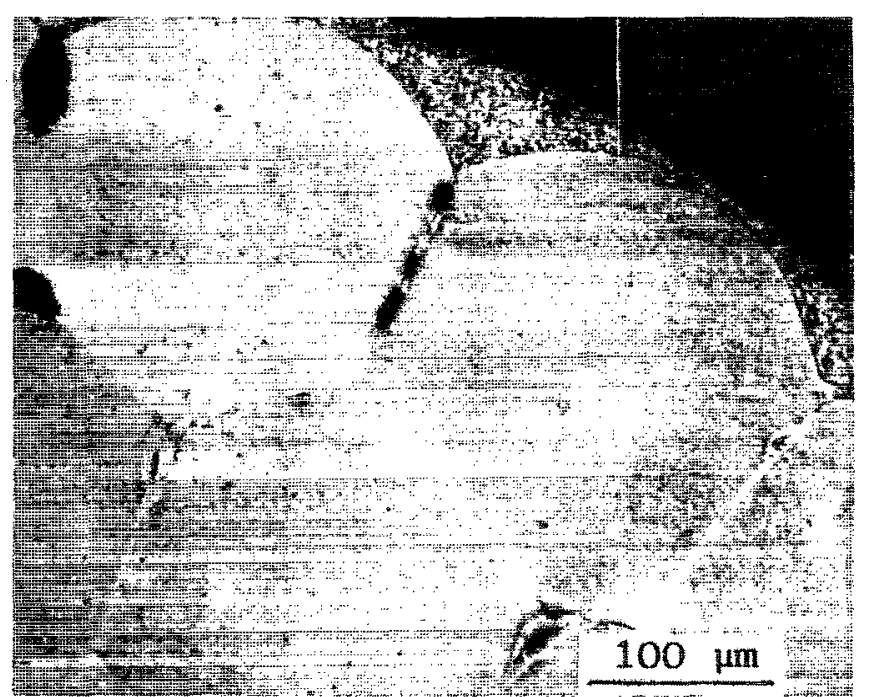

FIG. 14. Photomicrograph of explosive-implosive shock-compacted pickled low-carbon steel wires with random arrangement taken at the section perpendicular to the axis of the compact. The white, bright, thin layer around particles is the melting/welding interface.

significance when applicd to practical explosive consolidation of metal powder.

The experimental phenomena observed for thin wires (with diameter ranging between 300 and $500 \mu \mathrm{m}$ ) agree with those observed for thick wires. Also, the phenomena observed in our experiments have been observed in $316 \mathrm{~L}$ stainless-steel powder consolidation too, as shown in Fig. 15. Of course the phenomena observed on any section of the compact in a practical powder compact are not as typical and concentrated as those in consolidated bunched wires, because the powder is in random arrangement and the observed section is arbitrary.

Therefore, we may well say that the results obtained from two-dimensional experiments like those of Staudhammer and Murr $^{28}$ and also our own, ${ }^{29}$ are still of universal significance for explosive consolidation of metal powder, be-



FIG. 15. Microphotograph of explosive compact of $316 \mathrm{~L}$ stainless steel powder. 
cause they indeed show the relevant phenomena and general regularities in the process of dynamical consolidation of metal powders.

\section{CONCLUSIONS}

Under an explosive implosive shock-wave consolidation process a high-temperature flow of mass was concentrated on a very thin layer of particle surface. That is, most of the shock energy was deposited on a very thin layer near the particle boundary that leads to local melting, softening, nonmelting bounding, and jet forming. Which of these occurs depends on the local circumstance. Melting welding is the most common consolidating mechanism for metal powder with random arrangement, but excessive melting decreases consolidation quality.

To ensure consolidation quality of metal powder, i.e., to get a compact with better strength, a fresh clean particle surface is necessary. Therefore, sufficient attention to the surface treatment of metal powder must be paid. Cooling of the melting region is mainly as result of thermal conduction between surface and interior of particle. The regularity of microhardness distribution along the section perpendicular to axis of the compact is consistent with the regularity of the pressure distribution except in phase-transformation areas. The experimental results are qualitatively consistent with Williamson's numerical simulation result.

\section{ACKNOWLEDGMENTS}

Discussions with Professor Zhemin Zheng and Professor Qingming Tan are gratefully acknowledged. The authors would like to thank Professor Jinyuan Zhang, Professor Shanbing Yu, Dr. Hua Ding, and Professor Rongzheng Che for their help. This research was supported by the National Advance Materials Committee of China, the China National Science Foundation committee, and the Laboratory for Mechanics of Materials Processing, Institute of Mechanics, Chinese Academy of Sciences.

${ }^{\prime}$ T. J. Ahrens, N. Thadani, A. H. Mutz, T. Vreeland, Jr., R. B. Schwarz, J. A. Tyburczy, S. L. M. Shastri, and T. C. Peng, in Metallurgical Application of Shock-Wave and High-Strain-Rate Phenomena, edited by L. E. Murr, K. P. Staudhammer, and M. A. Meyers (Dekker, New York, 1986), p. 83.

${ }^{2}$ T. Vreeland, Jr., P. Kasiraj, A. H. Mutz, and N. N. Thadhani, in Metallurgical Application of Shock-Wave and High-Strain-Rate Phenomena, edited by L. E. Murr, K. P. Staudhammer, and M. A. Meyers (Dekker, New York, 1986), p. 231.

${ }^{3}$ J. H. Adair, R. R. Wills, and V. D. Linse, in Emergent Process Methods for High-Technology Ceramics, edited by R. F. Davis, H. Palmer III, and R. L. Porter (Plenum, New York, 1984), p. 639.
${ }^{4}$ A. Sawaoka, in Emergent Process Methods for High-Technology Ceramics, edited by R. F. Davis, H. Palmer III, and R. L. Porter (Plenum, New York, 1984), p. 793.

'E. K. Beauchamp, R. E. Loehman, R. A. Graham, B. Morosin, and E. L. Venturini, in Process Methods for High-Technology Ceramics, edited by $\mathbf{R}$. F. Davis, H. Paimer III, and R. L. Porter (Plenum, New York, 1984), p. 735.

${ }^{6}$ T. Z. Blazynski, in Metallurgical Applications of Shock-Wave and HighStrain-Rate Phenomena, edited by L. E. Murr, K. P. Staudhammer, and M. A. Meyers (Dekker, New York, 1986), p. 83.

${ }^{7}$ K. P. Staudhammer and K. A. Johnson, in Metallurgical Applications of Shock-Wave and High-Strain-Rate Phenomena, edited by L. E. Murr, K. P. Staudhammer, and M. A. Meyers (Dekker, New York, 1986), p. 149.

${ }^{*}$ G. E. Korth, J. E. Flinn, and R. C. Green, in Metallurgical Applications of Shock-Wave and High-Strain-Rate Phenomena, edited by L. E. Murr, K. P. Staudhammer, and M. A. Meyers (Dekker; New York, 1986), p. 129.

"V. F. Lotrich, T. Akashi, and A. Sawaoka, in Metallurgical Applications of Shock-Wave and High-Strain-Rate Phenomena, edited by L. E. Murr, K. P. Staudhammcr, and M. A. Mcyers (Dekker, New York, 1986), p. 293.

${ }^{10} \mathrm{~L}$. E. Murr, in Metallurgical Applications of Shock-Wave and HighStrain-Rate Phenomena, edited by L. E. Murr, K. P. Staudhammer, and M. A. Meyers (Dekker, New York, 1986), p. 329.

"P. Kasiraj, T. Vreeland, Jr., R. B. Schwarz, and T. J. Ahrens, Acta Metall. 32, 1235, (1984).

${ }^{12}$ W. H. Gourdin, J. Appl. Phys. 55, 172 (1984).

${ }^{13}$ W. H. Gourdin, Met. Trans. A 15, 1653 (1984).

${ }^{14} \mathrm{~V}$. D. Linse, in Metallurgical Applications of Shock-Wave and HighStrain-Rate Phenomena, edited by L. E. Murr, K. P. Staudhammer, and M. A. Meyers (Dekker, New York, 1986), p. 29.

${ }^{15}$ D. G. Morris, Mater. Sci. Eng. 57, 187 (1983).

${ }^{16}$ A. N. Staver, in Shock Waves and High-Strain-Rate Phenomena in Met$a l s$, edited by M. A. Meyers and L. E. Murr (Plenum, New York, 1981), p. 865.

${ }^{17} \mathrm{D}$. Raybould, in Shock Waves and High-Strain-Rate Phenomena, edited by M. A. Meyers and L. E. Murr (Plenum, New York, 1981), p. 895.

${ }^{18} \mathrm{R}$. Prummer, in Emergent Process Methods for High Technology Ceramics, edited by R. F. Davis, H. Palmer III, and R. L. Porter (Plenum, New York, 1984), p. 621.

${ }^{19}$ M. L. Wilkins, A. S. Kusubov, and C. F. Cline, in Metallurgical Applications of Shock-Wave and High-Strain-Rate Phenomena, edited by L. E. Murr, K. P. Staudhammer, and M. A. Meyers (Dekker, New York, 1986), p. 57.

${ }^{20}$ R. A. Berry and R. L. Williamson, in Shock Waves in Condensed Matter, edited by Y. M. Gupta (Plenum, New York, 1986), p. 337.

${ }^{21}$ R. L. Williamson and R. A. Berry, in Shock Waves in Condensed Matter, edited by Y. M. Gupta (Plenum, New York, 1986), p. 341.

${ }^{22}$ J. E. Flinn; R. L. Williamson, R. A. Berry, and R. N. Wright, J. Appl. Phys. 64, 1446 (1988).

${ }^{23}$ L. M. Milne-Thomson, Theoretical Hydrodynamics (Macmillan, New York, 1979).

${ }^{24}$ B. Shao, J. Gao, and G. Li, Explosion and Shock Waves, 9, 17 (1989) (in Chinese).

${ }_{25}^{25}$ J. D. Campbell and W. G. Ferguson, Philos. Mag. 21, 63 (1970).

${ }^{26}$ C. K. Godunov, A. A. Delebas, and B. E. Maly, Phys. Combust. Explos. 11, 3 (1975) (in Russian).

${ }^{27}$ J. Gao, K. Zhang, and Z. Zheng, Acta Metall. Sin. A 26, 202 (1990) (in Chinese).

${ }^{28}$ K. P. Staudhammer and L. E. Murr, J. Mater. Sci. 25, p. 2287 (1990).

${ }^{24}$ J. Gao, B. Shao, and Z. Zheng, Bull. Am. Phys. Soc. 34, p. 1729 (1989). 